\title{
Research on Energy Saving and Loss Reduction of Electricity in Construction Industry Yang Lianhui
}

\author{
(Power Research Institute of State Grid Jiangxi Electric Power Company)
}

\begin{abstract}
Keywords: Building electricity; Electric energy; Energy saving; Power supply and distribution; Lighting
\end{abstract}

\begin{abstract}
With the global energy crisis becoming more and more severe, the consciousness of saving energy and protecting the environment is deeply rooted in the hearts of the people, and the use of energy-saving technologies to reduce building energy consumption has become the focus of attention in the world. Energy consumption in China's construction industry is increasing day by day, especially in civil buildings, electrical lighting energy consumption accounts for a large proportion of the total energy consumption of buildings. Therefore, how to make effective use of lighting energy-saving technology, formulate feasible building lighting energy-saving schemes and reduce energy waste in civil building lighting is of great significance to the cause of energy conservation and emission reduction in China. This paper analyzes in detail the specific energy-saving strategies and measures in building electrical design from the aspects of power supply and distribution system energy saving, transformer energy saving, motor power system energy saving and lighting system energy saving, and summarizes them.
\end{abstract}

\section{Introduction}

With the development of society and the increase of population, the resources on the earth are becoming more and more scarce. China is a country with a large population which consumes a large amount of energy every year. China's per capita resources and energy resources are less than half of the world's per capita level, but China's building area energy consumption is $2-3$ times that of developed countries.It can be seen that there is still a lot of energy saving space in our country. It is of great significance to actively study the methods of building electrical energy conservation for environmental protection and sustainable development. Whether it is lighting system, power supply and distribution system or other electrical equipment, there is more energy-saving space.In order to achieve the effect of energy saving, building electrical technicians should set up scientific energy-saving ideas and take effective energy-saving measures to truly realize the economic operation of electrical equipment and power supply and distribution systems. This paper first expounds the principles that should be followed in building electrical energy conservation, then puts forward the energy conservation measures for lighting application and power motors and finally discusses several methods of electrical energy conservation.

\section{Development of Building Electrical Energy Conservation in China}

Building electricity is based on building technology and electrical technology, including strong and weak electricity. Among them, the strong electricity system mainly includes power transformation and distribution system (high and low voltage distribution system, transformer, emergency power supply system, etc.), power system, lighting system, lightning protection and grounding system, etc.

China's building energy conservation work started late, but it is gratifying to note that the energy waste problem in China's construction industry has received widespread attention from the society and attracted the attention of relevant departments and industries.China has implemented many design standards by force, such as Code for Acceptance of Building Energy Conservation Construction Quality, Green Building Evaluation Standard, Energy Efficiency Limits and Levels of Double - ended Fluorescent Lamps for General Lighting, Energy Efficiency Limits and Levels of Self - ballasted Fluorescent Lamps for General Lighting and Energy Efficiency Limits and Energy 
Efficiency Evaluation Values of Three - phase Distribution Transformers to achieve building electrical energy conservation. With the deepening of reform and opening-up and the integration with the international community, we have further seen our own gap and have gradually learned and used more advanced design concepts and technologies from abroad. For example, oil circuit breakers were first used in high-voltage switchgear, which were bulky and did not prevent fire. Now vacuum circuit breakers and SF6 circuit breakers are used.

After entering the $21^{\text {st }}$ century, intelligent lighting equipment is developing towards integration, and China's intelligent lighting industry is gradually maturing, which has promoted the development of building lighting energy-saving technology. At present, the relevant technical basis for building electrical lighting energy conservation has become increasingly mature, but because China has not yet formulated a perfect evaluation system for building electrical energy conservation, it is unable to strictly control the planning, design, construction and maintenance management stages in lighting projects, which hinders the development of building lighting energy conservation in China.

\section{Principles to be Followed in Building Electrical Energy Conservation}

In the construction project, we should not blindly use building electrical energy-saving technology, should not reduce the use demand for energy saving or the functions of the building, should not neglect the cost planning for energy saving. Therefore, we should follow the following principles in the energy-saving design of building electricity.

1.Practicality. Considering China's national conditions and actual economic conditions, we should not blindly ignore economic benefits for energy conservation. We should carefully compare the performance-price ratio of energy-saving materials and energy-saving equipment so that the investment in energy-saving can achieve ideal results and get corresponding returns. 2.Applicability.Electrical energy conservation must meet the comfort of building space and some special technological requirements, as well as the requirements of building on brightness and color temperature, whichare also requirements for the integrity of the artificial environment in the building. In addition, building electrical technology should also provide reasonable energy supply for the equipment in the building to meet the environmental requirements of the building. 3.Energy saving. The most critical and important step in building electrical energy-saving skills is to consider its energy efficiency. In order to avoid waste, effective measures must be taken.

\section{Research on Strategies of Building Electrical Energy Conservation Design}

In the power supply and distribution system, electrical equipment such as motors, transformers, ballasts for lamps and lanterns and many household appliances are inductive, which will generate lagging reactive current and be transmitted from the system to the end of the electrical equipment via high and low voltage lines, thus virtually increasing the power loss of lines.

The following measures can be taken to reduce this part of the loss: use electric equipment with high power factor as much as possible in the design, such as synchronous motors, etc.Inductive electrical equipment can be selected from electrical equipment with compensation capacitors, such as fluorescent lamps with capacitance compensation. Electrostatic capacitor can be used for reactive power compensation. The lead reactive current generated by the capacitor can offset the lag reactive current of the electrical equipment, thus achieving the goal of improving the power factor and reducing the overall reactive current. For power supply lines, the following aspects should be considered to reduce line losses: (1) As far as possible, choose the conductor with smaller resistivity; (2) The design line should go straight as far as possible and not go back as far as possible in low-voltage distribution. The substation should be close to the load center to reduce the power supply radius; (3) Increasing the cross-sectional area of the conductor will increase the line section by one level on the premise of satisfying the requirements of current carrying capacity, thermal stability, protection coordination and voltage drop for longer lines. Although the line cost will be increased, the annual operating cost will be reduced due to energy saving; (4) In the case of constant 
transmission power, because the power loss and the square of the current strength is proportional, and the power loss and the square of the operating voltage is inversely proportional. In the range of allowable fluctuations in the rated voltage, the appropriate increase in operating voltage can significantly reduce the power loss of the line.

1 Power supply and distribution system energy saving

Measures should be taken to increase the operating voltage and power factor of the system, reduce reactive power and resistance in conductors and reduce line losses in the power supply and distribution system. The main ways to save energy are:

(1) According to factors such as load capacity, power supply distance and distribution and characteristics of power equipment, reasonably design power supply and distribution system and select power supply voltage. Power supply and distribution system should be as simple and reliable as possible. The number of power transformation and distribution levels of the same voltage power supply system should not be more than two.

(2) Substations should be as close to the load center as possible to shorten the distribution radius and reduce line losses. Connection lines should be laid between substations within power users. According to the load situation, some transformers can be removed to reduce losses.

(3) Reduce line resistance, the selection of lines should be in line with international standards, promote the application of IEC287-3 - 2/1995 "economic optimization of power cable section" and reasonably select line section according to the economic current density method to reduce losses. In addition, for ring power mode, in order to reduce the resistance value of the line, changing the open network operation to the closed network operation can also significantly reduce line loss.

(4) The method of increasing voltage level can be adopted in transmission. According to the calculation, the line loss can be reduced by $17.4 \%$ when the voltage is increased by $10 \%$. Therefore, increasing the voltage transmission is an effective way to reduce the line loss.

(5) Increase power factor and reduce power loss. The line loss is inversely proportional to the 2 square of power factors of power users, so improving the power factor is also an effective measure to reduce the loss. To improve the power factor, we can start from two aspects: reasonable selection of electrical equipment capacity and installation of parallel compensation capacitors.

2 Energy Saving of Electrical Equipment

Energy saving of air conditioning system: The air conditioning system mainly saves energy from the following aspects. The first is to optimize the control of the ice storage system. Since the current ice storage system is not very advanced, it is still necessary to study the control methods of ice storage. The ice melting strategy can improve the energy utilization efficiency and promote the commercialization of cold storage technology to a certain extent. The second is the technology of controlling VAV system. The third is to optimize the control of the cooling system. The fourth is to optimally control the temperature difference and flow rate of the heat exchange system.

3 High Efficiency and Energy Saving Lighting Control Design

At present, there are several design methods for controlling high efficiency and energy saving: prism window, light guide tube, reflection high window and lighting shelf. Lighting control plays a very important role in the whole lighting control system design. It is part of the theoretical foundation and an important part of supporting the implementation of lighting energy conservation. The main reason is that lighting control can make the lighting environment comfortable and create a good light environment and different environment atmosphere by dividing the light space.

\section{Conclusion}

In short, whether it is power supply and distribution system, transformer system, motor power system, lighting system or other electrical equipment, it has great potential for energy saving. In order to achieve the goal of "saving energy and reducing power consumption", building electrical technicians should establish and perfect the energy-saving ideas, and through scientific management, careful consideration and repeated comparison of schemes, come up with a set of effective and practical energy-saving measures that do not only meet various technical indicators but also meet functional requirements, so as to achieve the goal of real energy saving. 


\section{References}

[1]Suárez-Cebador M, Rubio-Romero J C, López-Arquillos A. Severity of electrical accidents in the construction industry in Spain. Journal of Safety Research, 48, 63-70[J]. Journal of Safety Research, 2014, 48C:63-70.

[2]Linhao Y E, Dakai L I, Huang W, et al. Research and Application of Electric Prediction Method Considering the Electrical Characteristics of Different Industry[J]. New Technology \& New Process, 2015.

[3]Shen X W, Co E I. Excellence Characteristic Research of Excellence Enterprise[J]. Development \& Innovation of Machinery \& Electrical Products, 2014.[4]

[5]Huang Y. Research of Efficient Security Scheme in Wireless Network[J]. Lecture Notes in Electrical Engineering, 2014.

[6]Contreras J E, Rodriguez E A, Taha-Tijerina J. Nanotechnology applications for electrical transformers - A review[J]. Electric Power Systems Research, 2017, 143:573-584.

[7]Fokyew O, Ahmad H. Management of Change and Operational Excellence in the Electrical and Electronics Industry[J]. International Review of Management \& Business Research, 2014, 3.

[8] Kad M R S. IR thermography is a Condition Monitor Technique in industry[J]. International Journal of Advanced Research in Electrical Electronics \& Instrumentation Engineering, 2013, 2(3).

[9]Baad-Hansen L, Lu S, Kemppainen P, et al. Differential changes in gingival somatosensory sensitivity after painful electrical tooth stimulation[J]. Experimental Brain Research, 2015, 233(4):1109-1118.

[10]Hippel A V. Problems and progress in dielectric research[C]// Conference on Electrical Insulation. IEEE, 2016.

[11]Tao Z, Xue C, University J. The Cooperative Coupling Effect of Technology Innovation and Standardization on the Competitiveness of China' $\mathrm{s}$ Electrical Appliance Industry-An Empirical Research Based on BP Neural Network[J]. Journal of Industrial Technological \& Economics, 2016.

[12]Alonso M, Huang C H. High-efficiency electrical charger for nanoparticles[J]. Journal of Nanoparticle Research, 2015, 17(8):1-8.

[13]Cardelli E, Faba A. Magnetic material modeling for the optimization of the electrical machine design[C]// Aeit Conference - From Research To Industry: the Need for A More Effective Technology Transfer. IEEE, 2015:1-6.

[14]Sengupta A, Sengupta S. Institute-Industry Interface Workshop on Newly developed fabric flexural rigidity tester, yarn characterisation unit and fabric electrical insulation tester for technical textiles[J]. Indian Journal of Fibre \& Textile Research, 2015, 40(2):220-221.

[15]Zhu S F, Yin Z X. Research of Screw-Machine Electrical Control System Based on IPC[J]. Advanced Materials Research, 2014, 1044-1045:837-840. 